\title{
Letramento crítico no Ensino Médio: uma proposta didática sobre pós-fatos contra o Nordeste/nordestino(a) em aulas de Língua Portuguesa
}

\author{
Mariana Galdino Santana*
}

\section{Resumo}

Compreendemos que cabe à escola, e especialmente à docência de Língua Portuguesa, preparar alunos e alunas para uma leitura cuidadosa e responsiva da produção informacional e midiática, possibilitando um olhar crítico sobre a "objetividade" dos fatos, colaborando, desse modo, com a (re)construção e problematização de um sentimento de pertencimento a uma territorialidade, quando os textos para o ensino e a aprendizagem da linguagem têm como objeto de discurso uma região e seu povo. Assim, se sabemos que a disseminação de notícias falsas e de pós-verdades pode ocasionar vários danos à sociedade em geral e às pessoas especificamente, proponho-me, nesse artigo, à reflexão, em aulas de Língua Portuguesa, acerca da formação do letramento crítico de estudantes do Ensino Médio, a partir do trabalho com textos, informação midiática e a cultura do "pósfato" em que a temática seja o Nordeste e o(a)s nordestino(a) s. Para tanto, sugere-se um Plano de Ensino Mensal - a ser aplicado em momento posterior à divulgação deste trabalho com fito de construir uma leitura crítica e fomentar a formação de opinião a partir da recepção de "pós-fatos" que tomam como referente o Nordeste e o(a)s nordestino(a)s. O plano em questão prevê discutir com os alunos questões éticas, sociais e de formação do sujeito contemporâneo, interessado nos processos de ensino e de aprendizagem, em aulas de Língua Portuguesa, para a formação de leitor(a) crítico(a) diante da

\footnotetext{
Universidade Federal de Alagoas (UFAL). Mestra em Linguística pelo Programa de Pós-Graduação em Linguística e Literatura da Universidade Federal de Alagoas (PPGLL/UFAL). Professora de Língua Portuguesa, em caráter temporário, na Secretaria de Educação do Estado de Alagoas (SEDUC/AL). ORCID: https://orcid.org/0000-0002-9914-3188..
} 
(própria) territorialidade. Trata-se, nesse sentido, de uma pesquisa de caráter bibliográfico e propositivo que apresenta uma abordagem qualitativa.

Palavras-chave: Pós-verdade. Responsividade. Fake news. Letramento informacional e midiático. Ética.

\title{
Critical Literacy in High School: a Teaching Proposal On Post-Facts Against the Northeast/Northeastern in Portuguese Language Classes
}

\begin{abstract}
We understand that it is up to the school, and especially the Portuguese Language teaching, to prepare students for a careful and responsive reading of informational and media production, enabling a critical look at the "objectivity" of the facts, thus collaborating with construction and problematization of a feeling of belonging to a territoriality, when texts for teaching and learning the language have as object of discourse a region and its people. Thus, if we know that the dissemination of false news and post-truths can cause various damages to society in general and to people specifically, I propose, in this article, to reflect, in Portuguese Language classes, on the formation of critical literacy of high school students, from the work with texts, media information and the culture of the "post-fact" in which the theme is the Northeast and the Northeast. Therefore, a Monthly Teaching Plan is suggested - to be applied after the publication of this work - in order to build a critical reading and encourage the formation of opinion from the reception of "postfacts" that take as a reference the Northeast and the Northeast. The plan in question envisages discussing with students ethical, social and training issues for the contemporary subject, interested in teaching and learning processes, in Portuguese
\end{abstract}


language classes, for the formation of critical readers facing the (own) territoriality. In this sense, it is a bibliographical and propositional research that presents a qualitative approach.

Keywords: Post-truth. Responsiveness. Fake news. Informational and media literacy. Ethic

Recebido em: 20/09/2021 // Aceito em: 04/10/2021. 


\section{Introdução}

A processual transformação pela qual vive a produção da informação, incluindo as mídias digitais, afeta os mais variados campos da vida humana: profissional, acadêmica e pessoal. Essas implicações também estão relacionadas às formas de interação cotidianas que, em grande medida, se dão por meio das redes sociais, como Facebook, Twitter, YouTube, Instagram e WhatsApp, já que são mídias utilizadas como espaços para geração de conteúdo e espaços nos quais os usuários podem se posicionar sobre temas distintos e trocar mensagens, em tempo real ou não. Além disso, tais redes vêm se constituindo em ferramentas de formação de opinião pública e de poder (OTTONICAR et al., 2019), visto que a quantidade de seguidores e influência que um sujeito tem faz com que suas práticas discursivas se tornem discursos de autoridade sobre o outro.

No tocante à produção de informação midiática, em 2018, o Brasil foi considerado um dos maiores produtores, circuladores e consumidores de notícias falsas ${ }^{1}$ do mundo (ORTELLADO, 2018; DFNDR Lab, 2018). Um exemplo que merece destaque é o caso das eleições presidenciais de 2014, período no qual circularam notícias pautadas no "pós-fato" - termo empregado como sinônimo de Pós-verdade (D’ANCONA, 2018) e que se refere ao momento quando os apelos à emoção e às crenças exercem maior influência na opinião pública -, provocando ódio contra o Nordeste e o(a)s nordestino(a)s, acusados de terem eleito uma presidenta de esquerda.

A divulgação de um mapa no site G1, em que o NorteNordeste era destacado com a cor vermelha, simbolizando o

1 Entende-se por notícias falsas a manipulação de discursos visando interesses próprios. 
Letramento crítico no Ensino Médio: uma proposta didática sobre pósfatos contra o Nordeste/nordestino(a) em aulas de Língua Portuguesa

Partido dos Trabalhadores (PT), e as demais regiões, em azul (PSDB), situava a região Nordeste como a que deu a presidência a Dilma Rousseff, visando causar divisão social/regional e desmerecer a capacidade eleitoral crítica do(a)s nordestino(a)s, atribuindo a eles o estereótipo de incapacitado(a)s.

Ao longo da história, tal como discute Albuquerque Jr. (2011), o Nordeste tem sido alvo de preconceitos e estereótipos e tem sido visto como o lugar da ignorância, da seca, da fome e da miséria, visão defendida pelo jornalista Mainardi em comentário à Globo News em 2014, após as eleições presidenciais. Em tal fala, o jornalista afirma que o Nordeste sempre foi retrógrado, governista, bovino e subalterno em relação ao poder; uma região atrasada e pouco educada/instruída.

Nesse ínterim, a proposta desta pesquisa está inserida dentro da temática dos letramentos e oportuniza a reflexão sobre as relações de poder manifestadas pela linguagem, pois, conforme aponta Coulmas (2014), o letramento continua sendo um vetor de desigualdade, definidor da posição social de sujeitos, o que possibilita à esfera pública o maior controle da opinião pública. Aqui, entendemos que letramento(s) são práticas sociais críticas e situadas de leitura e escrita, sendo estas atreladas ao modelo denominado de "ideológico" (STREET, 2014). Nesse sentido, o letramento varia de acordo com cada contexto político, social, histórico e ideológico.

De modo específico, neste trabalho, abordar-se-á a pósverdade (aqui entendida como sinônimo de pós-fato), que, tomando como base as ideias de D'Ancona (2018), referese ao momento "quando os apelos à emoção, a crenças e a ideologias têm mais influência em moldar a opinião pública que os fatos objetivos [...]". Assim, considerando essa nova era 
de desinformação, as necessidades de letramento da sociedade contemporânea dizem respeito ao letramento informacional e midiático, tendo em vista a gama de enunciados nos quais estamos imersos na web.

Dessa maneira, o letramento crítico e a instauração de uma conduta ética são grandes desafios, pois exigem à docência, em específico a de Língua Portuguesa, que leve em consideração perspectivas históricas e transculturais, de modo que suas práticas de letramento engajem os sujeitos a construírem sentidos na vida social (PINHEIRO, 2007). Assim, viabilizar o pensamento crítico, ético e responsivo e problematizar a veracidade dos fatos na sociedade da (des)informação são tarefas árduas, embora essa realidade não deva provocar descrédito do alcance de tal fim.

Nesse processo de leitura crítica, um dos papéis das aulas de Língua Portuguesa é ensinar que é necessário produzir sentidos sobre os fatos que acessamos, além de fomentar a prática de escrita com as reflexões produzidas, situando a discussão em um contexto local, regional e nacional, no sentido de que esses discursos mapeados e analisados se referem a nossa territorialidade, nesse caso, a do Nordeste. Diante dessa necessidade, analisar a veracidade das informações geradas e veiculadas pelas mídias é algo complexo, pois requer uma reformulação no ethos (CHARAUDEAU, 2011), ${ }^{2}$ ou seja, uma mudança no comportamento dos sujeitos que recebem/ compartilham tais dados.

Em vista disso, esta pesquisa intenta propor um Plano de Ensino para a disciplina de Língua Portuguesa, a ser aplicado em sala de aula em momento posterior à divulgação deste trabalho, com fito de construir uma leitura crítica e fomentar a formação

2 A noção de ethos assumida nesta pesquisa é a de ethos discursivo (CHARAUDEAU, 2011), visto como uma prática de influência sobre o outro, objetivando a persuasão. 
de opinião a partir da recepção de "pós-fatos" que tomam como referente o Nordeste e o(a)s nordestino(a)s. Trata-se, nesse sentido, de uma pesquisa de caráter bibliográfico e propositivo que apresenta uma abordagem qualitativa.

As investigações deste trabalho foram motivadas pela seguinte questão de pesquisa: 1) Como docentes podem proporcionar uma formação de leitores e escritores críticos e responsivos a partir do trabalho com oficinas, parte de uma proposta de sequência didática, sobre "pós-fatos" e fake news que tenham como objeto o Nordeste/nordestino(a) em aulas de Língua Portuguesa, de modo a favorecer o multiletramento, quando problematiza o sentimento de pertencimento a uma territorialidade?

O presente estudo é justificado pela necessidade de que, em aulas de Língua Portuguesa, sejam inseridas aulas específicas para tratar da recepção de informações, tomando como base o "pós-fato". Considerando que é na escola que ajudamos a formar a consciência ética e o pensamento crítico dos cidadãos, este se torna um ambiente propício para a implementação de uma metodologia que dialogue com a vida desses sujeitos.

Assim, por meio da proposta de Plano de Ensino, esperase auxiliar na construção de competências necessárias para um letramento informacional e midiático, a fim de que os discentes sejam capazes de construir pensamento crítico em relação aos fatos que acessamos diariamente, especialmente em relação aos discursos sobre o Nordeste/nordestino(a), possibilitando um sentimento de pertencimento a essa territorialidade. Para tal propósito, foram eleitos os campos da saúde e da política para a seleção dos discursos que são analisados, visto que são esferas da comunicação que, em grande medida, produzem e circulam "pós-fatos". 
A partir disso, é possível oferecer aos docentes de Língua Portuguesa do Ensino Médio insumos para que esses agentes possam contribuir com a formação de estudantes para agirem em variados campos de atuação social, como o da vida pessoal, da pública, da pesquisa e do jornalístico-midiático, sugerindo experiências significativas, capazes de transformar a vida desses sujeitos e o meio em que vivem. Tal efeito é possível a partir de práticas de linguagem e da construção de uma consciência crítica e seletiva em relação à produção e à circulação de informações na mídia digital, por meio das compreensões, reflexões e mudanças/ rupturas.

Nesse sentido, devido ao contexto sociocultural, político e ideológico instaurado na atual (ciber)cultura - em que prevalece o relativismo -, o tema torna-se cada vez mais emergente e necessário, devendo ser explorado nas mais variadas esferas da sociedade, sobretudo no eixo educacional.

Dada as considerações iniciais, apresento a seguir o arcabouço teórico que fundamentou este estudo.

\section{0 comportamento da língua(gem) no contexto da pós- -verdade}

\subsection{Linguagem e responsividade}

As noções de texto, língua(gem) e sujeito que estão subjacentes a este lugar teórico-metodológico estão vinculados aos estudos propostos por Bakhtin e seu círculo. O texto é tomado como enunciado concreto, situado em um dado contexto sociocultural. A noção de língua adotada aqui é a de língua como 
ação e dialogia. Particularmente, a noção de língua assumida neste trabalho baseia-se na ideia de língua como ação e interação. Conforme Faraco (2009), apoiando-se na concepção bakhtiniana, a língua é tomada como signo ideológico que refletem e refratam uma dada realidade. Nesse sentido, os signos não apenas descrevem o mundo, mas constroem diversas interpretações a respeito dele. Assim, “[a] palavra está sempre repleta de conteúdo e de significação ideológica ou cotidiana [...]" (VOLÓCHINOV, 2018, p. 181). Diante dessa compreensão, todo enunciado é dialógico e estabelece uma interação discursiva entre sujeitos. Assim, a linguagem é uma atividade dialógica e, na interação estabelecida pelo diálogo, os sujeitos agem na/sobre a língua de forma responsável. A responsividade assumida por sujeitos nas práticas sociais caracteriza-se pela adesão ao dizer de outrem, por exemplo, em notícias.

Com base nessa discussão, é importante pensar sobre como ocorre a organização discursiva dos enunciados que produzimos socialmente. Ao fazermos uso da língua, sempre o fazemos por meio de um determinado gênero discursivo. Tal afirmação significa que, ao produzir um texto, é preciso estar atento às características de composição, às funcionalidades e ao contexto comunicativo. Primariamente, os gêneros do discurso têm como propósito atender às demandas comunicacionais. Unido a esse propósito, os gêneros também possuem o papel de organizar os textos/discursos. Nesse sentido, cada texto/discurso pertence a um gênero determinado e emerge de esferas do conhecimento específicas.

Sendo a produção de textos uma ação contextualizada, cada objeto produzido tem um meio de circulação específico e é arraigado em questões sociais, políticas, ideológicas e culturais 
do sujeito que o produziu, já que é construído dentro de uma comunidade histórico-social. As esferas da comunicação são variadas, bem como a diversidade de gêneros existentes. Para citar alguns exemplos, temos a esfera do cotidiano, na qual circulam textos não especializados, como um bilhete, uma conversa etc., e a esfera científica, na qual circulam textos especializados, como artigos acadêmicos, livros, teses etc., sendo que cada um desses textos é produzido de acordo com os objetivos da esfera comunicativa em que estão inseridos. Nessa perspectiva, Bakhtin (2011, p. 262) define os gêneros do discurso como "tipos relativamente estáveis de enunciados [...]". Tal definição permite-nos compreender que, além dos aspectos funcionais, os gêneros se organizam por questões linguísticodiscursivas.

Nesse viés, as contribuições desses conceitos bakhtinianos para o contexto educacional apresentam um papel de extrema importância, visto que formar sujeitos para agir de forma responsiva e responsável, diante de práticas sociais hegemônicas que perpetuam forças centrípetas de poder e dominação, faz com que as práticas discursivas se rasurem e se ressignifiquem. Em suma, assumir uma postura responsiva diante de discursos mentirosos, como os que circulam atualmente nas mais variadas esferas e que são materializados em diversos gêneros, possibilita uma educação permeada por sujeitos éticos que lutam pela justiça e pela verdade objetiva.

\subsection{A ética como um ato responsável}

Tendo em vista o objetivo desta pesquisa - que é propor um Plano de Ensino para a disciplina de Língua Portuguesa com fito de construir uma leitura crítica e fomentar a formação de 
Letramento crítico no Ensino Médio: uma proposta didática sobre pósfatos contra o Nordeste/nordestino(a) em aulas de Língua Portuguesa

opinião a partir da recepção de "pós-fatos" que tomam como referente o Nordeste e o(a)s nordestino(a)s -, faz-se necessário compreender o conceito de ética, haja vista que a formação de um pensamento ético é parte fundamental para o alcance de tal propósito.

A ética é um princípio de valor que busca dar conta do problema humano de saber qual a melhor maneira de agir no mundo, ou seja, como devo agir para que minha vida seja a melhor possível com o outro, aspecto relevante para a formação cidadã (CORTELLA, 2010). Bakhtin (2017) encontrou dois problemas nos sistemas éticos, de conteúdo e de forma, ou seja, teoréticos; Precisou, então, lançar mão de uma concepção que pudesse dar resposta a essa questão e que tratasse do problema do existir humano em um mundo mergulhado na contingência e no devir. Com intuito, Bakhtin compreende que:

[...] o ato deve encontrar um único plano unitário para refletir-se em ambas as direções, no sentido e em seu existir, deve encontrar a unidade de uma responsabilidade bidirecional, seja em relação ao conteúdo (responsabilidade especial), seja em relação ao seu existir, (responsabilidade moral). (BAKTHIN, 2017, p. 43)

A proposta de Bakhtin para solucionar esse impasse parte da compreensão de que o ato deve estar de acordo com o pensamento para que possa ser um ato moral, ou seja, um ato responsável, pois, dessa maneira, ele forma um "todo integral: tanto o (pensamento enquanto ato) seu conteúdo-sentido quanto o fato de sua presença em minha consciência real de um ser humano singular precisamente determinado e em condições determinadas [...]" (BAKHTIN, 2017, p. 44). De acordo com Fiorin 
A teoria pretende analisar o mundo em sua totalidade abstratamente unificada e, portanto, fracassa na apreensão do ato em sua singularidade e em sua unicidade. O que Bakhtin pretende fazer é criar uma filosofia primeira que leve em conta o evento, o acontecimento historicamente real e singular. (FIORIN, (2011, p. 207).

Ao estabelecer que um ato responsável é o que está em acordo com o pensamento (sendo este um juízo de validade universal), surge uma outra questão (problema): se o pensamento é o juízo de validade universal, só por meio dele podemos agir de maneira responsável. O pensamento julga para que possamos saber como agir, mas o juízo acontece quando valoramos e ponderamos sobre como deve ser nosso agir. Para Bakhtin,

A valoração do pensamento como ato individual leva em consideração, e, contém em si, de forma plena, o momento da validade teórica do pensamento-juízo; a valoração do significado do juízo; a valoração do significado do juízo constitui um momento necessário na efetivação do ato, apesar de não exaustivo. (BAKTHIN, 2017, p. 44).

Um ato responsável é um ato pensado, resultado de um deliberar; este é responsável pois é individual, apenas meu. Contudo, para chegar a um juízo que tenha validade universal, tenho que realizar a valoração do significado do meu juízo, "momento necessário para sua efetivação [...]" (BAKHTIN, 2017, p. 45). Mas, para que um juízo seja necessário (imperativo) para mim, não basta ter validade teórica, para que seja um juízo de dever para mim "devo pensar veridicamente; veridicidade ou ser-verdadeiro é o dever de pensar [...]" (BAKHTIN, 2017, p. 22). Desse modo, a filosofia bakhtiniana, marcada dentro do contexto da tradição filosófica russa, se interessa pela questão moral. 
Letramento crítico no Ensino Médio: uma proposta didática sobre pósfatos contra o Nordeste/nordestino(a) em aulas de Língua Portuguesa

Destaco, também, a compreensão das formas de verdade como base para pensar a assimilação de discursos mentirosos na internet, conforme é pensada por Bakhtin na utilização dos termos russos - istina e pravda. A palavra istina diz respeito à verdade universal (científica), já a palavra pravda está relacionada à verdade singular, única e irrepetível de cada sujeito a partir do contexto e da posição que ele ocupa. $\mathrm{O}$ ato mobiliza essas duas formas de verdade, elas o constituem. Mas o que vem a ser um ato? Para Bakhtin, em sua etimologia:

"Postupok" é um ato, de pensamento, de sentimento,
de desejo, de fala, de ação, que é intencional, e
que caracteriza a singularidade, a peculiaridade, o
monograma de cada um, em sua unicidade, em sua
impossibilidade de ser substituído, em seu dever
responder, responsavelmente, a partir do lugar que
ocupa, sem álibi e sem exceção (BAKHTIN, 2017, p.
10, grifos meus).

Com base na reflexão acerca da noção de ato apresentada por Bakhtin (2017), uma ação responsável é tida como ato, pois o que caracteriza o ato responsável é a assinatura do sujeito, aspecto que diverge na cibercultura, pois prevalece o anonimato. Assim, a partir dessa reflexão, compreendemos que uma ação, quando não é responsável, tende a estar mais ligada à abstração do conhecimento; ao contrário, quando se torna responsável, a ação tende a dialogar com o mundo da vida dos sujeitos, que assinam e se responsabilizam pelo ato de pensar, pois é a minha aproximação a determinado conteúdo que me faz assinar por ele eticamente.

De acordo com Amorim (2009, p. 21), o que está em debate é a seguinte questão: "Qual é a ética de um pensamento? Ou ainda: em que condições um pensamento teórico pode ser ético?". A partir dessa dimensão ética em jogo, afirma-se que, embora um conteúdo teórico (científico) possa ser verdadeiro, isso não garante que ele seja ético, pois: 
$\mathrm{O}$ ato de pensar é sempre singular e diz respeito a um sujeito único. Somente o ato de pensar pode ser ético, pois é nele que o sujeito é convocado. Enquanto abstração, o único dever da teoria é ser verdadeira. Mas o próprio dever de buscar a verdade, aquilo que me obriga a pensar verdadeiramente enquanto estou pensando, não decorre do conteúdo do pensamento, mas do ato de pensar. Uma teoria verdadeira, ao virar ato, isto é, ao ser pensada por alguém singular e único, vira ética. E pode, assim, completar sua verdade universal com a verdade singular a que Bakhtin chama de pravda (AMORIM, 2009, p. 22).

$\mathrm{O}$ reconhecimento de que um determinado conhecimento tem validade para mim é o que confirma a minha assinatura nele, pois me reconheço nele. A palavra pravda já significou justiça, equidade, notadamente porque se consideram as singularidades dos sujeitos e como os seus discursos podem afetar a vida de outros sujeitos, portanto estes devem se posicionar responsavelmente. A verdade istina tem sua validação em si mesma. É preciso destacar que uma verdade universal somente se torna válida se considerar um contexto individual, é o conjunto dessas verdades singulares que completam o valor universal.

A concretude do meu ato singular se dá na articulação com as diferenças, cada sujeito é um centro de valores. Assim, é com esses múltiplos centros que devo responder com meus atos. $\mathrm{O}$ dever de pensar como ato manifesta o não álibi do ser, que diz respeito ao fato de o sujeito não se eximir da sua responsabilidade. "Preciso reconhecer um conhecimento como meu, como algo que diz respeito ao meu lugar e que, portanto, me leva a assinálo [...]" (AMORIM, 2009, p. 33, grifos do autor).

Mediante tais reflexões, espera-se que o conceito complexo de "ato" possa estabelecer sentido para os posicionamentos tomados pelos alunos, sobre a responsabilidade diante do 
Letramento crítico no Ensino Médio: uma proposta didática sobre pósfatos contra o Nordeste/nordestino(a) em aulas de Língua Portuguesa

ato de pensar, de acordo com a aplicação do plano de ensino proposto no terceiro tópico deste artigo. Esse tipo de debate destaca-se pela necessidade que os sujeitos têm de posicionar-se responsavelmente

\subsection{A cibercultura como berço da pós-verdade}

O mundo digital está repleto de links, caminhos que, embora estejam ali para serem acessados por nós, não dominamos, ou seja, nós permitimos que arquitetem os nossos próximos passos. Em vista disso, somos manipulados digitalmente o tempo todo em virtude dos cliques de damos. Conforme apresenta o dicionário Oxford (2016), a definição de pós-verdade diz respeito à "circunstância em que os fatos objetivos são menos influentes em formar a opinião pública do que os apelos às emoções e à crença pessoal [...]". No entanto, vale salientar que o termo não é sinônimo de mentira. Nessa nova era da comunicação, a validade do que seja verdadeiro ou falso não se relaciona mais com as questões da ética e da moral, mas com recursos argumentativos que validam ou não um discurso.

As fake news (notícias falsas/enganosas/manipuladas) há muito já fazem parte do cotidiano das sociedades. Porém, a discussão atual na qual se insere esta pesquisa diz respeito à recepção e à validação dos fatos feita pelos estudantes. A leitura do que pode ser considerado verdade ou mentira se ressignificou ao longo do tempo, e o que importa mesmo é o meu fato contra o seu fato. Nesse sentido, o ato de ler tornou-se mais complexo na cibercultura. A liberação do polo de informação, a liberdade da informação, a participação e o compartilhamento ainda não encerraram seus cabedais de transformações. A sociedade 
hiperconectada em redes é descentralizada e indomável. Nessa perspectiva, a educação é um caminho seguro para a verdade e a ética.

O que acontece de fato é o que Wardle e Derakhshan (2017) chamam de "desordem informacional", ou seja, formas de manipulação da informação. Tais formas de manipulação são classificadas de acordo com o grau de veracidade. Nesse sentido, uma informação pode ser considerada totalmente falsa, parcialmente falsa ou pode apresentar conteúdo manipulado, havendo grandes prejuízos quando se trata de um discurso de ódio ou vazamento de informações pessoais. Essa questão também põe em xeque a ética jornalística, já que os produtores de informações enganosas nem sempre levam em consideração a veracidade dos fatos $\mathrm{e}$, sim, o apelo à sensibilidade do consumidor da notícia.

$\mathrm{Na}$ era da pós-verdade, um hiato se estabelece entre sentimento e fato; acreditamos naquilo que queremos acreditar, naquilo que nos é oportuno. No entanto, a grande preocupação, conforme nos aponta D'Ancona, está no fato de que:

[...] as mentiras, as manipulações e as falsidades
políticas enfaticamente não são o mesmo que a pós-
verdade. A novidade não é a desonestidade dos políticos,
mas a resposta do público a isso. A indignação dá lugar
à indiferença e, por fim, à conivência. A mentira é
considerada regra, e não exceção [...]. (D’ANCONA,
2018, p. 34).

Com tal argumento, o jornalista revela que a pós-verdade não se relaciona com a desonestidade, a corrupção, pois estas nuanças estão há muito arraigadas em nossas culturas. O que de fato reflete essa nova era de desinformação é a resposta ou refratação do público a discursos obscuros e injustos. Outro 
aspecto a ser observado é o fato de a indiferença dos sujeitos em relação à corrupção e às mentiras deixar subentendido uma certa conivência com a propagação fraudulenta de discursos. A cultura dos chamados "fatos alternativos" é uma realidade que deve ser encarada pela sociedade como um problema ético e que carece de formação humana. A desconfiança na sociedade atual deu lugar à falta de objetividade e racionalidade no que concerne às escolhas políticas, o que se pensa é mais ou menos o seguinte: "todo político é corrupto e mente, logo, aquele que me parece mais 'autêntico' e 'franco', talvez, resolva os meus anseios e esperança". Essa mentalidade alimenta a fábrica de mentiras e nos mostra o descrédito dado à verdade objetiva dos fatos. Numa sociedade assim, o contra-ataque não está na tensão que ocorre dentro dessa arena de discursos, mas em torno de uma construção de consciência coletiva que enaltece valores tão caros à uma sociedade democrática: a ética, a justiça e a verdade.

Nesse ínterim, a tarefa dos fatos alternativos é a de semear dúvidas e inconclusões a respeito dos fatos tornandoos desconfiáveis, para que a sociedade se mantenha distante do objetivismo. Como nos aponta o jornalista investigativo Ari Rabin-Havt (apud D'Ancona 2018, p. 46): "Essas mentiras são parte de um ataque coordenado e estratégico, planejado para esconder a verdade, confundir o público e criar controvérsia onde nenhuma antes existia [...]”. Assim, o interesse está em ludibriar os sujeitos, causando-lhes uma espécie de paranoia informacional. O objetivo é simples, manter acessa uma discussão e assegurar que nunca cheguem a uma conclusão.

A bolha informacional a qual a web nos submete nos faz reforçar nossas opiniões e tornar as mentiras incontestáveis, pois ela é um terreno indiferente à veracidade das coisas. Nesse 
contexto, o que importa é que os discursos pareçam verdadeiros e causem grande repercussão. A assimilação que se faz desses discursos é tendenciosa, pois procuramos e clicamos naquilo que pretendemos encontrar. Nesse sentido, a força do populismo está assentada no sentimento e não em evidências. Daí nascem as "teorias da conspiração", pois as crenças assumem lugar de liderança em relação à razão objetiva.

A negação da ciência é também uma arma da pós-verdade. Confia-se menos em investigações consistentes, baseadas em provas, do que numa coleção de anedotas que podem ter consequências fatais para a humanidade. Considerando-se a internet como uma fonte significativa de busca de informações, o nicho provocado pelos filtros que as redes fazem de acordo com o perfil de cada sujeito pode, porém, gerar uma passividade que compromete a análise e a investigação de informações advindas de diferentes campos e instituições.

No contexto atual, notícias a respeito dos "tratamentos" da covid-19 têm mobilizado sujeitos a fazerem uso de medicamentos de forma desregrada. Alguns médicos(as), em nome da "ciência", têm prestado um desserviço com a divulgação de medicamentos supostamente indicados para combater o vírus. E, de posse dessas informações, aparentemente confiáveis, já que vinham de profissionais da saúde, a população, devido aos apelos à emoção e à urgência da cura, submete-se à ingestão de fármacos que pouco ou nada têm a ver com a possível eliminação/prevenção da doença.

Mentir, definitivamente, não é só uma questão de enganar ou esconder um fato pessoal indesejável. Conforme observa com maestria o dr. Wilbur Larch em As regras da Casa de Sidra, de John Irving (apud D’Ancona 2018, p. 80): “Quando você mente, isso faz você se sentir no comando de sua vida. 
Letramento crítico no Ensino Médio: uma proposta didática sobre pósfatos contra o Nordeste/nordestino(a) em aulas de Língua Portuguesa

Contar mentiras é muito sedutor para os órfãos. Eu sei. [...] Eu sei porque também as conto a eles. Adoro mentir. Ao mentir, você sente como se tivesse enganado o destino: o seu próprio e o de todo mundo [...]". Desse modo, a mentira pode ser um artefato de recuperação de poder.

\section{Plano de ensino: uma proposta didática para o letra- mento informacional de estudantes do ensino médio}

Para o cumprimento dos propósitos deste artigo, proponho, no quadro a seguir, um Plano de Ensino Mensal para a disciplina de Língua Portuguesa que poderá ser adotado, principalmente, por docentes do Ensino Médio que pertençam ou que tenham interesse sobre os discursos produzidos acerca do Nordeste e do(a)s nordestino(a)s. A escolha desse nível de ensino justifica-se pela compreensão de que lidamos com sujeitos mais maduros, alunos que estão prestes a adentrar no universo acadêmico da universidade e precisam chegar a esse espaço com uma mentalidade ética e moral, com uma formação crítica de letramento.

A seguir, apresento o Plano de Ensino Mensal: 


\section{Quadro 1 - Plano de Ensino Mensal}

\begin{tabular}{|c|c|c|}
\hline \multicolumn{3}{|l|}{ 1. IDENTIFICAÇÃO } \\
\hline $\begin{array}{l}\text { Componente curricular: } \\
\text { Língua Portuguesa }\end{array}$ & $\begin{array}{l}\text { Ano/Série: Ensino } \\
\text { Médio }\end{array}$ & Escola/Instituição: \\
\hline $\begin{array}{l}\text { Período de } \\
\text { desenvolvimento: dia, } \\
\text { mês e ano de início e de } \\
\text { término. }\end{array}$ & $\begin{array}{l}\text { Carga Horária: } 12 \\
\text { horas }\end{array}$ & Professor(a): XXXXXXX \\
\hline \multicolumn{3}{|l|}{ 2. EMENTA } \\
\hline \multicolumn{3}{|c|}{$\begin{array}{l}\text { - } \quad \text { Refletir sobre a noção de verdade; } \\
\text { - Compreender a construção discursiva baseada em "pós-fatos" sobre o Nordeste e o(a) } \\
\text { s nordestino(a)s; } \\
\text { - Possibilitar uma leitura crítica de discursos mentirosos sobre essa territorialidade; } \\
\text { - Desenvolver habilidades de análise critica de discursos mentirosos. }\end{array}$} \\
\hline
\end{tabular}

\section{REFERÊNCIAS}

III Seminário Humanidade em Tempo de Pandemia - A epidemia de fake News. YouTube: uspfflch, 17 jul. 2020. 1 vídeo (1 h. 30 min. 35 s.). Publicado por Faculdade de Filosofia, Letras e Ciências Humanas da Universidade de São Paulo. Disponível em: https://www.youtube.com/ watch?v=O4pq33sXj9w. Acesso em: 24 ago. 2020.

ALBUQUERQUE JR., Durval Muniz de. A invenção do Nordeste e outras artes. 2011. São Paulo: Cortez.

BAKHTIN, Mikhail M. Para uma filosofia do ato responsável. Tradução de Valdemir Miotello \& Carlos Alberto Faraco. São Carlos: Pedro \& João Editores, 2017.

BRAHIM, Adriana Cristina S. de Mattos. Pedagogia crítica, letramento crítico e leitura crítica.

REVISTA X, v.1, 2007.

DIANA Luz Pessoa. Campinas: Abralin. Publicado por Abralin, 11 maio 2020. 1 vídeo (1h 56 min. 20 s.). Disponível em: https://www.youtube.com/watch?v=le2T8Tk1t-c. Acesso em: 24 ago. 2020.

D'ANCONA, Mathew. Pós-Verdade: a nova guerra contra os fatos em tempos de fake news. Barueri: Faro Ediorial, 2018.

STREET, Brian V. Letramentos sociais: Abordagens críticas do letramento no desenvolvimento, na etnografia e na educação. São Paulo: Parábola. 2014.

VOLÓCHINOV, Valentin. Marxismo e filosofia da linguagem: problemas fundamentais do método sociológico na ciência da linguagem. Tradução, notas e glossário de Sheila Grillo e Ekaterina Vólkova Américo; ensaio introdutório de Sheila Grillo. 2. ed. São Paulo: Editora 34, 2018. 
Letramento crítico no Ensino Médio: uma proposta didática sobre pósfatos contra o Nordeste/nordestino(a) em aulas de Língua Portuguesa

\begin{tabular}{|c|c|c|c|c|c|}
\hline \multicolumn{6}{|c|}{ 4. CRONOGRAMA DE ATIVIDADES } \\
\hline DATA & OBJETIVOS & CONTEÚDOS & CH & METODOLOGIA & AVALIAÇÃO \\
\hline $\begin{array}{l}\text { De (dia } \\
/ \text { mês) } \\
\text { a (dia / } \\
\text { mês) de } \\
\text { (ano). }\end{array}$ & $\begin{array}{l}\text { Refletir sobre a } \\
\text { noção de verdade; } \\
\text { compreender o } \\
\text { contexto da pós- } \\
\text { verdade; } \\
\text { Desenvolver } \\
\text { habilidades de; } \\
\text { Possibilitar a } \\
\text { prática de leitura e } \\
\text { de diálogo. }\end{array}$ & $\begin{array}{l}\text { Noção de } \\
\text { verdade; } \\
\text { O que é pós- } \\
\text { verdade?; } \\
\text { Fake news e } \\
\text { internet. }\end{array}$ & $3 \mathrm{~h}$ & $\begin{array}{l}\text { As aulas serão } \\
\text { ministradas a } \\
\text { partir de uma } \\
\text { concepção de língua } \\
\text { sociointeracionista e } \\
\text { de uma perspectiva } \\
\text { dialógica da } \\
\text { linguagem, de } \\
\text { base bakhtiniana. } \\
\text { Nestas, toma-se } \\
\text { como foco o uso de } \\
\text { Metodologias Ativas, } \\
\text { possibilitando ao } \\
\text { aluno o protagonismo } \\
\text { na construção de seu } \\
\text { próprio conhecimento. } \\
\text { Como recursos } \\
\text { didáticos, serão } \\
\text { utilizados slides, } \\
\text { textos, músicas, } \\
\text { podcasts e vídeos. }\end{array}$ & $\begin{array}{l}\text { Serão utilizados } \\
\text { como critérios } \\
\text { avaliativos: } \\
\text { partipação nos } \\
\text { fóruns de discussão; } \\
\text { participação } \\
\text { nos encontros } \\
\text { síncronos; grau de } \\
\text { envolvimento no } \\
\text { processo de ensino; } \\
\text { apreensão dos } \\
\text { saberes propostos } \\
\text { e envolvimento } \\
\text { das habilidades } \\
\text { almejadas. } \\
\text { Como recurso } \\
\text { avaliativo, os alunos } \\
\text { farão leitura de } \\
\text { materiais diversos } \\
\text { e produzirão um } \\
\text { fichamento. }\end{array}$ \\
\hline $\begin{array}{l}\text { De } \\
\text { (dia / } \\
\text { mês) } \\
\text { a (dia } \\
/ \text { mês) } \\
\text { de } \\
\text { (ano). }\end{array}$ & $\begin{array}{l}\text { Compreender } \\
\text { como se } \\
\text { constrói a matriz } \\
\text { discursiva } \\
\text { hegemônica } \\
\text { sobre o } \\
\text { Nordeste e o(a)s } \\
\text { nordestino(a)s; } \\
\text { Mapear } \\
\text { discursos } \\
\text { mentirosos } \\
\text { sobre essa } \\
\text { territorialidade e } \\
\text { os sujeitos desta } \\
\text { região. }\end{array}$ & $\begin{array}{l}\text { A invenção do } \\
\text { Nordeste; } \\
\text { Discursos } \\
\text { hegemônicos } \\
\text { sobre o } \\
\text { Nordeste e o(a)s } \\
\text { nordestino(a)s; } \\
\text { esconstruindo } \\
\text { a visão } \\
\text { determinista } \\
\text { sobre o } \\
\text { Nordeste e o(a)s } \\
\text { nordestino(a)s. }\end{array}$ & $3 \mathrm{~h}$ & $\begin{array}{l}\text { As aulas serão } \\
\text { ministradas a } \\
\text { partir de uma } \\
\text { concepção de língua } \\
\text { sociointeracionista e } \\
\text { de uma perspectiva } \\
\text { dialógica da } \\
\text { linguagem, de } \\
\text { base bakhtiniana. } \\
\text { Nestas, toma-se } \\
\text { como foco o uso de } \\
\text { Metodologias Ativas, } \\
\text { possibilitando ao } \\
\text { aluno o protagonismo } \\
\text { na construção de seu } \\
\text { próprio conhecimento. } \\
\text { Como recursos } \\
\text { didáticos, serão } \\
\text { utilizados slides, } \\
\text { textos, músicas, } \\
\text { podcasts e vídeos. }\end{array}$ & $\begin{array}{l}\text { Serão utilizados } \\
\text { como critérios } \\
\text { avaliativos: } \\
\text { partipação nos } \\
\text { fóruns de discussão; } \\
\text { participação } \\
\text { nos encontros } \\
\text { síncronos; grau de } \\
\text { envolvimento no } \\
\text { processo de ensino; } \\
\text { apreensão dos } \\
\text { saberes propostos } \\
\text { e desenvolvimento } \\
\text { das habilidades } \\
\text { almejadas. } \\
\text { Como recurso } \\
\text { avaliativo, os alunos } \\
\text { farão a leitura dos } \\
\text { discursos mentirosos } \\
\text { mapeados sobre } \\
\text { Nordeste e o(a)s } \\
\text { nordestino(a)s dos } \\
\text { campos da saúde e } \\
\text { da política. }\end{array}$ \\
\hline
\end{tabular}




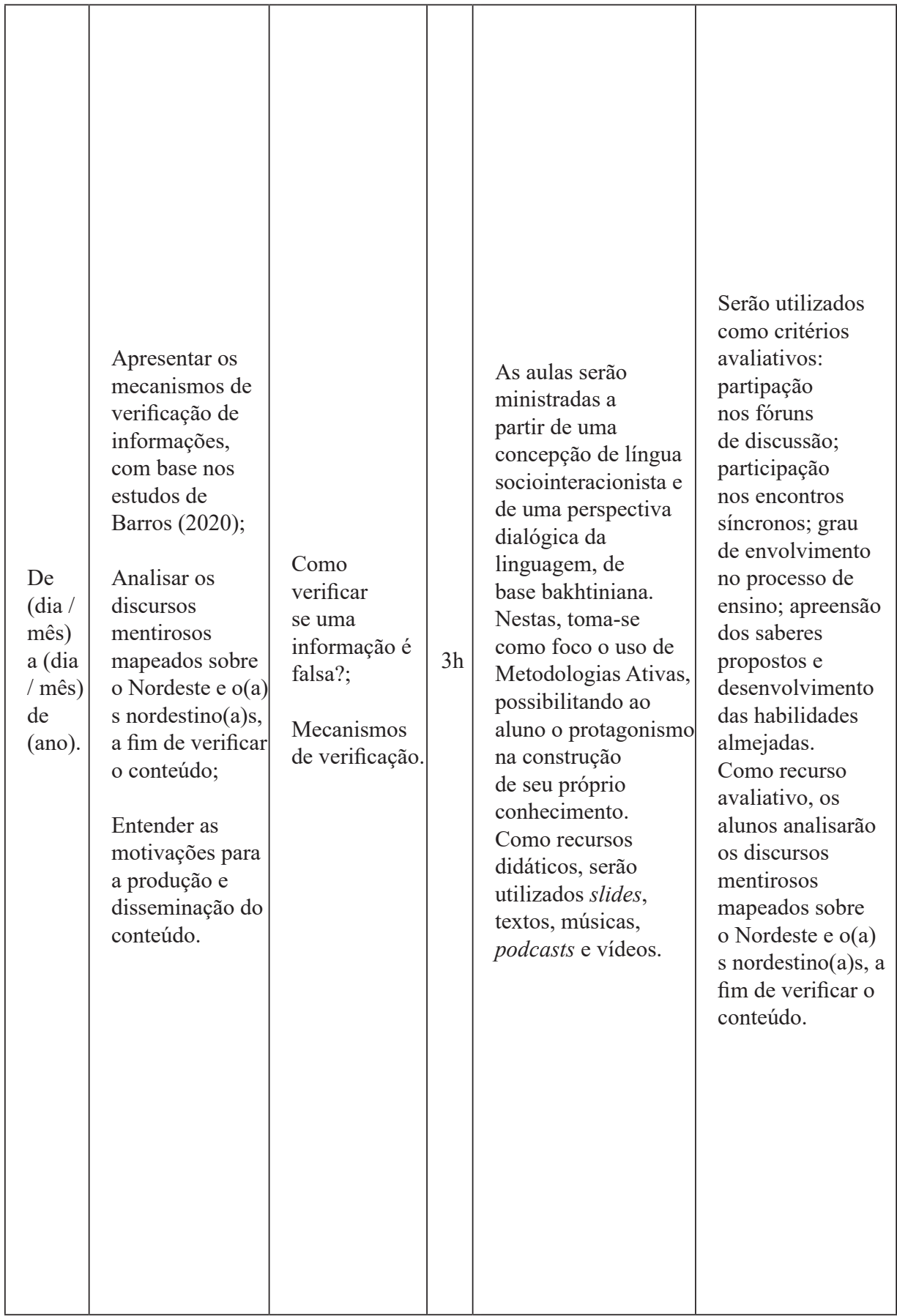


Letramento crítico no Ensino Médio: uma proposta didática sobre pósfatos contra o Nordeste/nordestino(a) em aulas de Língua Portuguesa

\begin{tabular}{|c|c|c|c|c|c|}
\hline $\begin{array}{l}\text { De (dia } \\
/ \text { mês) } \\
\text { a (dia / } \\
\text { mês) de } \\
\text { (ano). }\end{array}$ & $\begin{array}{l}\text { Produzir uma } \\
\text { análise crítica } \\
\text { sobre as reflexões } \\
\text { empreendidas; } \\
\text { Publicar tais } \\
\text { produções em um } \\
\text { blog da disciplina. }\end{array}$ & $\begin{array}{l}\text { Produzindo um } \\
\text { texto analítico. }\end{array}$ & $3 \mathrm{~h}$ & $\begin{array}{l}\text { As aulas serão } \\
\text { ministradas a } \\
\text { partir de uma } \\
\text { concepção de língua } \\
\text { sociointeracionista e } \\
\text { de uma perspectiva } \\
\text { dialógica da } \\
\text { linguagem, de } \\
\text { base bakhtiniana. } \\
\text { Nestas, toma-se } \\
\text { como foco o uso de } \\
\text { Metodologias Ativas, } \\
\text { possibilitando ao } \\
\text { aluno o protagonismo } \\
\text { na construção de seu } \\
\text { próprio conhecimento. } \\
\text { Como recursos } \\
\text { didáticos, serão } \\
\text { utilizados slides, } \\
\text { textos, músicas, } \\
\text { podcasts e vídeos. }\end{array}$ & $\begin{array}{l}\text { Serão utilizados } \\
\text { como critérios } \\
\text { avaliativos: } \\
\text { partipação nos } \\
\text { fóruns de discussão; } \\
\text { participação } \\
\text { nos encontros } \\
\text { síncronos; grau de } \\
\text { envolvimento no } \\
\text { processo de ensino; } \\
\text { apreensão dos } \\
\text { saberes propostos } \\
\text { e desenvolvimento } \\
\text { das habilidades } \\
\text { almejadas. } \\
\text { Como recurso } \\
\text { avaliativo, os } \\
\text { alunos produzirão } \\
\text { uma análise crítica } \\
\text { contendo entre } \\
30 \text { e } 50 \text { linhas } \\
\text { sobre as reflexões } \\
\text { empreendidas a ser } \\
\text { publicada em um } \\
\text { blog da disciplina. }\end{array}$ \\
\hline
\end{tabular}

Fonte: Elaborado pela autora (2021)

Conforme exposto nesse Plano de Ensino, após a ministração de aulas teóricas para a contextualização do período da pós-verdade e para o (re)conhecimento dos discursos sobre o Nordeste, o mapeamento de pós-fatos seria realizado pelo(a) docente da disciplina, tendo como exemplo o comentário feito pelo jornalista Diogo Mainardi (DIOGO, 2014) - citado na introdução deste artigo -, fala que não condizia e não condiz com a realidade vivenciada nesta região.

Após a leitura e a análise desses pós-fatos sobre o Nordeste, os alunos escreveriam uma análise a ser publicada em um blog (espaço pensado devido ao cunho educativo e formal dessa ferramenta) como forma de compartilhar os saberes produzidos com outros sujeitos. 
Com este Plano de Ensino Mensal, espera-se que o(a) docente possa fomentar uma formação crítica de estudantes do Ensino Médio diante das informações acessadas em contextos digitais.

\section{Considerações finais}

Tendo em vista a grande incidência da produção e da difusão de informações falsas e/ou manipuladas, consolidadas pelas redes sociais, as famílias, a educação, as mídias e os demais setores da sociedade têm um novo desafio: o de educar para a ética e para a criticidade.

A produção de verdades tem sido cada vez mais relativizada, causando prejuízos aos fundamentos da pós-modernidade. Pensar na produção de verdades como uma questão responsiva e ética é tarefa fundamental possibilitada pela escola/universidade a partir de um conhecimento organizado e fundamentado. Construir um olhar atento às produções de informações sobre a nossa territorialidade é engajar os cidadãos de uma determinada comunidade a pensar sobre os discursos que constroem o seu lugar de modo crítico. Desse modo, o letramento informacional colabora com a formação de sujeitos comprometidos com a produção de verdades.

Nessa perspectiva, o plano de ensino sugerido para inserção em aulas de Língua Portuguesa intenta discutir com os alunos questões éticas, sociais e de formação do sujeito contemporâneo, com foco nos processos de ensino e de aprendizagem, para a formação de leitor(a) crítico(a) diante da (própria) territorialidade. Portanto, além de formar um aluno crítico e responsivo, essa proposta colabora também para a construção de um sentimento de pertencimento, favorável ao zelo e ao comprometimento com o objeto de ensino. 
Letramento crítico no Ensino Médio: uma proposta didática sobre pósfatos contra o Nordeste/nordestino(a) em aulas de Língua Portuguesa

\section{Referências}

ALBUQUERQUE JR., Durval Muniz de. A invenção do Nordeste e outras artes. 2011. São Paulo: Cortez.

AMORIM, Marília. Para uma filosofia do ato: "Válido e inserido no contexto". In.: BRAIT, Beth (org.). Bakhtin, dialogismo e polifonia. São Paulo: Contexto, 2009.

BAKHTIN, Mikhail M. Para uma filosofia do ato responsável. Tradução de Valdemir Miotello \& Carlos Alberto Faraco. São Carlos: Pedro \& João Editores, 2017.

BAKHTIN, Mikhail M. Estética da criação verbal. Prefácio à edição francesa Tzvetan Todorov; introdução e tradução do russo Paulo Bezerra. 6. ed. São Paulo: Editora WMF Martins Fontes, 2011.

BARROS, D. L. P. de. As fake news e as anomalias. VERBUM - Cadernos de Pós Graduação, v. 9, n. 2, p. 26-41, set. 2020.

CHARAUDEAU, Patrick. Discurso político. Tradução de Fabiana Komesu e Dilson Ferreira da Cruz. 2. ed. São Paulo: Contexto, 2011.

COULMAS, Florian. Escrita e Sociedade. Tradução de Marcos Bagno. São Paulo: Parábola Editorial, 2014.

CORTELLA. Mario Sergio. Qual é a tua obra?: inquietações propositivas sobre gestão, liderança e ética. 9 ed. Petrópolis, RJ: Vozes, 2010.

D'ANCONA, Mathew. Pós-Verdade: a nova guerra contra os fatos em tempos de fake news. Barueri: Faro Ediorial, 2018.

DFNDR LAB. Relatório da segurança digital no Brasil: segundo trimestre de 2018. 2018. Disponível em: https:// www.psafe.com/dfndr-lab/wp-content/uploads/2018/08/ Relat\%C3\%B3rio-da-Seguran\%C3\%A7a-Digital-no-Brasil-2trimestre-2018.pdf. Acesso em: 15 ago. 2019. 
DIANA Luz Pessoa. Campinas: Abralin. Publicado por Abralin, 11 maio 2020. 1 vídeo (1h 56 min. 20 s.). Disponível em: https:// www.youtube.com/watch?v=le2T8Tk1t-c. Acesso em: 24 ago. 2020 .

DIOGO Mainardi: Eleição da Dilma e Nordeste - 27/10/2014. Documentaryondemand, 27 jul. 2014. 1 vídeo (2 min. 33 s.). Publicado por Documentaryondemand. Disponível em: https:// www.youtube.com/watch?v=MRC-SPPSJOE. Acesso em: 30 ago. 2020 .

DOLZ, Joaquim; NOVERRAZ, Michele; SCHNEUWLY, Bernard. Seqüências didáticas para o oral e a escrita: apresentação de um procedimento. In: SCHNEUWLY, Bernard.; DOLZ, Joaquim. e colaboradores. Gêneros orais e escritos na escola. Tradução e organização de Roxane Rojo e Glaís Sales Cordeiro. Campinas-SP: Mercado de Letras, 2004.

FARACO, Carlos Alberto. Linguagem \& Diálogo: as ideias linguísticas do círculo de Bakhtin. São Paulo: Parábola Editorial, 2009.

FIORIN, J. L. Resenha Bakhtiniana. São Paulo, v.1, n ${ }^{0}$ 5, p. 205-209, $1^{\circ}$ semestre 2011.

G1. Dilma vence em 15 estados, Aécio em 9 e no DF, e Marina, em 2; veja mapa. Disponível em: http://g1.globo.com/politica/ eleicoes/2014/blog/eleicao-em-numeros/post/dilma-vence-em15-estados-aecio-em-9-e-no-df-e-marina-em-2-veja-mapa.html. Acesso em: 20 set. 2021.

MOITA LOPES, Luiz Paulo da (org.). Por uma Linguística Aplicada Indisciplinar. São Paulo: Parábola Editorial, 2006.

MONTEIRO, Rosemeire Selma. A Linguística Aplicada e o processo de letramento. Rev. De Letras, v. 1/2, n. 21, jan./dez. 1999.

ORTELLADO, Pablo. Brasil esteve na 'vanguarda' das fake news. Veja, São Paulo, 11 de mai. 2018. Disponível em: https:// 
Letramento crítico no Ensino Médio: uma proposta didática sobre pósfatos contra o Nordeste/nordestino(a) em aulas de Língua Portuguesa

veja.abril.com.br/tveja/em-pauta/pablo-ortellado-brasil-estevena-vanguarda-das-fake-new. Acesso em: 15 ago. 2019.

OTTONICAR, Selma Leticia Capinzaiki et al. Fake news, big data e o risco à democracia: novos desafios à competência em informação e midiática. In: ENCONTRO IBÉRICO EDICIC, 9. 2019, Barcelona. Anais [...]. Barcelona, 2019.

OXFORD. Palavra do ano 2016. 2016. Disponível em: https:// languages.oup.com/word-of-the-year/2016. Acesso em: 04 out. 2021.

PINHEIRO, Petrilson Alan. Construções sociais de gênero no ciberespaço: novas práticas sociais de letramento. Revista de Estudos da Linguagem, Belo Horizonte, v. 15, n. 1, p. 129-146, jan./jun. 2007.

RAJAGOPALAN, Kanavillil. Repensar o papel da Linguística Aplicada. In: LOPES, Luiz Paulo da Moita (org.). Por uma Linguística Aplicada Indisciplinar. São Paulo: Parábola Editorial, 2006.

STREET, Brian V. Letramentos sociais: Abordagens críticas do letramento no desenvolvimento, na etnografia e na educação. São Paulo: Parábola. 2014.

VOLÓCHINOV, Valentin. Marxismo e filosofia da linguagem: problemas fundamentais do método sociológico na ciência da linguagem. 2. ed. São Paulo: Editora 34, 2018.

WARDLE, Claire; DERAKHSHAN. Information disorder: Toward an interdisciplinary framework for faracresearch and policy making. Council of Europe, 2017. 